\title{
Diagnostic and therapeutic hysterolaparoscopy in evaluation and treatment of female infertility in a tertiary hospital
}

\author{
Sasmita Behuria, Rohani Nayak* \\ Department of Obstetrics and Gynaecology, S.C.B. Medical College, Cuttack, Odisha, India \\ Received: 26 October 2016 \\ Revised: 01 November 2016 \\ Accepted: 03 November 2016 \\ *Correspondence: \\ Dr. Rohani Nayak, \\ E-mail: rohanirinky@gmail.com \\ Copyright: (C) the author(s), publisher and licensee Medip Academy. This is an open-access article distributed under \\ the terms of the Creative Commons Attribution Non-Commercial License, which permits unrestricted non-commercial \\ use, distribution, and reproduction in any medium, provided the original work is properly cited.
}

\begin{abstract}
Background: To corroborate the findings of hystero-laparoscopy for evaluation of female infertility in a tertiary hospital over a period of 18 months. This study is intended to review the effectiveness of combining diagnostic hysteroscopy and laparoscopy in predicting the prevalence of different lesions with accuracy and taking appropriate therapeutic measures.

Methods: This is a prospective study conducted at the Dept of O and GSCB Medical College, Cuttack, Odisha over a period of 18 months (April 2014 to October 2015). Those infertile women where the period of infertility was more than 2 years with optimum male factor were subjected to diagnostic hysteroscopy and laparoscopy under general anaesthesia.

Results: Of 235 cases recruited $64 \%$ were having primary infertility and 36\% were having secondary infertility.46\% had hysteroscopic abnormality and 39.5\% had laparoscopic abnormality. Among the abnormal hysteroscopy cases septate uterus was highest and among laparoscopic finding peritoneal adhesions was highest. All the cases undergoing DTHL were discharged on the next day with no major complication except 2 cases which were managed at the same time.

Conclusions: DTHL is an effective and safe procedure for female infertility evaluation. This can be taken as a gold standard method in those whose infertility is more than 2 years.
\end{abstract}

Keywords: Diagnostic and therapeutic, Hystero-laparoscopy, Infertility

\section{INTRODUCTION}

Infertility is defined as inability to conceive after 1 year of unprotected sexual intercourse (Speroff). ${ }^{1}$ The stigma of childlessness is so intense that the woman deserves the best method of evaluation with less expense and more result. Though the incidence of infertility has not changed over the last 3 decades the diagnostic modalities have improved in the last few years. Though DTHL is not the initial investigational tool it should be definitely be offered to patients after a period of 2 year infertility since now-a-days woman are more career oriented and ambitious there are reproductive options at a later age.
With the conventional investigations like HSG, USG, Sonohysterogram and Sonosalpingography, abdominopelvic adhesions, endometriosis and pelvic inflammations are missed. Even after bilateral free spillage found in the HSG, patient doesn't conceive. It is the normal pelvic anatomy which is the key factor for conception. The tubo-ovarian alignment is important for ovum pick up. Genital tuberculosis, one of the very important causes of infertility in India, is usually missed in HSG, but can be easily diagnosed with laparoscopy. ${ }^{2}$ So our study intends to highlight the effectiveness of DTHL in evaluating female infertility. 


\section{METHODS}

235 patients complaining of infertility more than 2 years attending Gynaecology OPD of SCB MCH, Cuttack, a tertiary care hospital, were included in our study for a period of 18 months (April 2014 to October 2015). All the routine investigations and complete hormonal profile and evaluation for male factors were done. All patients having normal hormonal profile, no male factor abnormality, no contraindication to the procedure and have lived together for more than 2 years were included in the study.

All patients were between the ages of $20-40$ years. These women were subjected to diagnostic and therapeutic hystero-laparoscopy under general anaesthesia after anaesthesiology evaluation. It was done in the proliferative phase (between 8-10 days of menstrual cycle). The diagnostic hysteroscopy was done with a 4 $\mathrm{mm}, 30$ degree fiber-optic rigid hysteroscope with a 5 mm diagnostic sheath. The distension media was normal saline. After distending the cavity, endocervical cavity, anterior and posterior wall, fundus and both cornu visualised. Any abnormal structures like polyp, myoma, septum, sub-septum, synechiae were identified. While visualising the cornu, both ostia and proximal part of fallopian tube are visualised and appropriate therapeutic measures were taken in the same setting.

Laparoscopy was done with one $10 \mathrm{~mm}$ and one $5 \mathrm{~mm}$ port. With 30 degree telescope pelvis inspected in a systematic manner including uterus, fallopian tube, round ligaments, uterovesical pouch, uterosacral ligaments, and pouch of douglas. The tubes were inspected for any abnormality in their length and shape. Both ovaries were inspected regarding their size, shape and thickness of peripheral follicles, evidence of ovulation, and their relationship with fimbrial end of tubes. Peritubal, periovarian and omental adhesions, tubo-ovarian (TO) masses, endometriotic deposits, fibroid, presence of fluid in the pouch of douglas or any pathology, if present was noted. Another $5 \mathrm{~mm}$ port was inserted in cases where abnormalities were detected for proper intervention. The tubal patency was ascertained by injecting methylene blue into the uterine cavity and its spill through the fimbrial ends (chromopertubation). Restricted or forced spillage was also noted. After closure of port site, dilation and curettage (D and $\mathrm{C}$ ) was done and endometrium sent for HP study.

\section{RESULTS}

Our study evaluated a total of 235 patients. Among them primary infertility comprises of $150(63.8 \%)$ cases and secondary infertility comprises $85(36 \%)$ cases (Table 1$)$. The mean age for primary infertility is 28 year and for secondary is 33 year.
Table 1: Types of infertility.

\begin{tabular}{|lll|}
\hline Types & No. & $\%$ \\
\hline Primary & 150 & 64 \\
\hline Secondary & 85 & 36 \\
\hline Total & 235 & 100 \\
\hline
\end{tabular}

Amongst the primary infertility patients, abnormality was found in $52(35 \%)$ cases and amongst the secondary infertility abnormality was $56(66 \%)$ in hysteroscopy whereas it was $58(39 \%)$ and $35(41 \%)$ respectively in laparoscopy (Table 2).

Table 2: Findings in hysterolaparoscopy.

\begin{tabular}{|lllll|}
\hline Type & Hystero & Scopy & Laparo & Scopy \\
\hline & Normal & Abnormal & Normal & Abnormal \\
\hline $\begin{array}{l}\text { Primary } \\
(\mathrm{n}=150)\end{array}$ & $\begin{array}{l}98 \\
(65 \%)\end{array}$ & $52(35 \%)$ & $\begin{array}{l}92 \\
(61 \%)\end{array}$ & $58(39 \%)$ \\
\hline $\begin{array}{l}\text { Secondary } \\
(\mathrm{n}=85)\end{array}$ & $\begin{array}{l}29 \\
(34 \%)\end{array}$ & $56(66 \%)$ & $\begin{array}{l}50 \\
(59 \%)\end{array}$ & $35(41 \%)$ \\
\hline Total & $\begin{array}{l}127 \\
(54 \%)\end{array}$ & $\begin{array}{l}108 \\
(46 \%)\end{array}$ & $\begin{array}{l}142 \\
(60.4 \%)\end{array}$ & \begin{tabular}{l}
$(39.5 \%)$ \\
\hline
\end{tabular} \\
\hline
\end{tabular}

The most common hysteroscopic pathology was septate and sub-septate uterus and its incidence being common in both primary $(22 \%)$ and secondary infertility (22\%). Other attributing pathologies in hysteroscopy were submucous myoma $(5.5 \%)$, endometrial polyp $(8.5 \%)$, bicornuate uterus $(3 \%)$, synechiae $(6 \%)$ and 2 forgotten IUCD (Table 3).

Table 3: Abnormal hysteroscopic findings.

\begin{tabular}{|llll|}
\hline Type & $\begin{array}{l}\text { Primary } \\
(\mathbf{n = 1 5 0})\end{array}$ & $\begin{array}{l}\text { Secondary } \\
(\mathbf{n = 8 5})\end{array}$ & $\begin{array}{l}\text { Total } \\
(\mathrm{n}=235)\end{array}$ \\
\hline Septum & $33(22 \%)$ & $19(22 \%)$ & $52(22 \%)$ \\
\hline Myoma & $4(3 \%)$ & $9(10.5 \%)$ & $13(5.5 \%)$ \\
\hline Polyp & $12(8 \%)$ & $8(9 \%)$ & $20(8.5 \%)$ \\
\hline $\begin{array}{l}\text { Bicornuate } \\
\text { uterus }\end{array}$ & $2(1.3 \%)$ & $5(9 \%)$ & $7(3 \%)$ \\
\hline Foreign body & 0 & $2(2 \%)$ & $2(0.85 \%)$ \\
\hline Synechiae & $1(0.6 \%)$ & $13(15 \%)$ & $14(6 \%)$ \\
\hline Total & $52(35 \%)$ & $56(66 \%)$ & $108(46 \%)$ \\
\hline
\end{tabular}

Out of all the factors in laparoscopy, the pelvic and peritoneal factors $(14 \%)$ accounts for highest followed by ovarian factors $(11 \%)$ (Table 4$)$.

Table 4: Abnormal laparoscopic findings.

\begin{tabular}{|llll|}
\hline $\begin{array}{l}\text { Type of } \\
\text { abnormality }\end{array}$ & Primary & Secondary & Total \\
\hline Tubal & 9 & 6 & $15(6 \%)$ \\
\hline Uterine & 8 & 12 & $20(8.5 \%)$ \\
\hline Pelvic peritoneal & 20 & 13 & $33(14 \%)$ \\
\hline Ovarian & 21 & 4 & $25(11 \%)$ \\
\hline Total & 58 & 35 & $93(39.5 \%)$ \\
\hline
\end{tabular}


The most common pathology in laparoscopy was endometriosis $(11 \%)$ in primary infertility and peritoneal and tuboovarian adhesions $(15 \%)$ in secondary infertility. Hydrosalpinx was found in 4 cases where 2 cases had bilateral and 2 cases had unilateral hydrosalpinx. On chromopertubation there was no spillage in the corresponding side in unilateral case and no spillage on both sides in bilateral cases. Other laparoscopic abnormalities detected were myoma (4\%), ovarian cyst (4\%), PCOD (3\%), tubal block (both bilateral and unilateral) $(7 \%)$, bicornuate uterus $(0.85 \%)$ and adhesions (10\%) (Table 5).

Table 5: Laparoscopic abnormalities.

\begin{tabular}{|llll|}
\hline & $\begin{array}{l}\text { Primary } \\
(\mathbf{n = 1 5 0})\end{array}$ & $\begin{array}{l}\text { Secondary } \\
(\mathbf{n = 8 5})\end{array}$ & $\begin{array}{l}\text { Total } \\
(\mathbf{n = 2 3 5})\end{array}$ \\
\hline Endometriosis & $16(11 \%)$ & $5(6 \%)$ & $21(9 \%)$ \\
\hline Adhesion & $11(7 \%)$ & $13(15 \%)$ & $24(10 \%)$ \\
\hline Myoma & $6(4 \%)$ & $4(8 \%)$ & $10(4 \%)$ \\
\hline Malformation & $2(1 \%)$ & 0 & $2(0.85 \%)$ \\
\hline $\begin{array}{l}\text { Tubal block, } \\
\text { hydrosalpinx }\end{array}$ & $8(5 \%)$ & $8(9 \%)$ & $16(7 \%)$ \\
\hline Pcod & $6(4 \%)$ & $1(1 \%)$ & $7(3 \%)$ \\
\hline Ovarian cyst & $7(5 \%)$ & $3(3.5 \%)$ & $10(4 \%)$ \\
\hline T0 mass & $2(1 \%)$ & $1(2.8 \%)$ & $3(1 \%)$ \\
\hline Total & $58(39 \%)$ & $35(41 \%)$ & $93(39.5 \%)$ \\
\hline
\end{tabular}

During the procedures necessary therapeutic measures were taken like polypectomy, myomectomy (2.5\%), septum resection (15\%) during hysteroscopy. During laparoscopy adhesiolysis (15\%), ovarian drilling (3\%), ovarian cystectomy $(3 \%)$, tubal cannulation $(3 \%)$ and myomectomy was done as per the pathology detected (Table 6).

Table 6: Procedure done during laparohysteroscopy.

\begin{tabular}{|llll|}
\hline procedure done & $\begin{array}{l}\text { Primary } \\
(\mathbf{n = 1 5 0 )}\end{array}$ & $\begin{array}{l}\text { Secondary } \\
(\mathbf{n = 8 5})\end{array}$ & $\begin{array}{l}\text { Total } \\
(\mathrm{n}=235)\end{array}$ \\
\hline Adhesiolysis & $20(13 \%)$ & $16(19 \%)$ & $36(15 \%)$ \\
\hline Drilling & $6(4 \%)$ & $1(1 \%)$ & $7(3 \%)$ \\
\hline Cystectomy & $5(3 \%)$ & $3(3.5 \%)$ & $8(3 \%)$ \\
\hline Septal resection & $23(15 \%)$ & $13(15 \%)$ & $36(15 \%)$ \\
\hline $\begin{array}{l}\text { Tubal } \\
\text { cannulation }\end{array}$ & $3(2 \%)$ & $4(5 \%)$ & $7(3 \%)$ \\
\hline $\begin{array}{l}\text { Polypectomy, } \\
\text { myomectomy }\end{array}$ & $4(3 \%)$ & $2(2 \%)$ & $6(2.5 \%)$ \\
\hline
\end{tabular}

\section{DISCUSSION}

In our study the most common pathology was endometriosis followed by peritoneal adhesions similar to the study by Prasant et al and Tsuji et al. ${ }^{3,4}$ Endometriosis and peritoneal adhesions distorts the tubo-ovarian relationship and prevents the ovum pick up even though the tubes are normal The golden rule in suspected patients with endometriosis is visual confirmation through laparoscopy (as mild endometriosis can only be detected on laparoscopy) before labelling a patient with endometriosis and starting treatment. ${ }^{5}$ In the study conducted by Godinjak et al where they studied 360 cases and the commonest factor responsible for infertility were adhesions and myoma. ${ }^{6}$ But overall peritoneal adhesions seems to be an important factor. In the study conducted by Puri et al, the commonest attributable cause for infertility was PCOD (ovarian factor) which was $22 \%$ of the whole population while it was only $3 \%$ in our case which may be due to different ethnicity and regional differences. $^{7}$

Uterine pathology accounts for $8.5 \%$ in our cases. Uterine pathologies are the cause of infertility in as many as $15 \%$ of couples seeking treatment and are diagnosed in as many as $50 \%$ of infertile patients. ${ }^{8-11}$ Septate and subseptate uterus are the commonest hysteroscopic abnormality attributing to infertility. Though per se they are not the primary cause for infertility and are usually associated with pregnancy loss but the high incidence in our study is due to inclusion of sub-septate uterus. Now days due to advent of hysteroscopic septal resection, simultaneous diagnosis and treatment can be done in same setting.

Other abnormalities detected were myoma and polyp, and in many cases polypectomy as well as myomectomy was done to improve outcome. A prospective study of 224 infertile women who underwent hysteroscopy observed a $50 \%$ pregnancy rate after polypectomy. ${ }^{12}$ Another study by Hinckley et al who did hysteroscopy in 1000 cases and found that $22 \%$ had endometrial polyp and concluded that a significant percentage of patients had uterine pathology detected by routine hysteroscopy that may impair the success of fertility treatment. ${ }^{13}$ In our study out of 93 abnormal cases in laparoscopy interventions were done in 51 cases and out of 108 abnormal cases in hysteroscopy interventions were done in 49 cases. Minor complications occurred in only 2 cases like omental vessel injury which was secured with cautery and another port site haematoma which was secured with sutures.

\section{CONCLUSION}

Diagnostic and therapeutic hystero-laparoscopy is a safe and effective method for infertile patients and at the same time can help to decide further plan of action without undue delay.Also the complications in the hands of experts are negligible so eligible patients should be offered this technique before initiation of definitive management.

\section{ACKNOWLEDGEMENT}

The authors would like to thank all the nursing staff of the operation theatre and all the patients who participated, making this study possible.

Funding: No funding sources

Conflict of interest: None declared 
Ethical approval: The study was approved by the Institutional Ethics Committee

\section{REFERENCES}

1. Speroff, Leon; Fritz, Marc A. Clinical gynecologic endocrinology and infertility. $8^{\text {th }}$ ed. Philadelphia: Lippincott Williams and Wilkins; Chapter 27, Female Infertility; 2005:1137.

2. Sharma JB. In vitro fertilization and embryo transfer in female genital tuberculosis. IVF Lite. 2015;2:1425 .

3. Nayak PK, Mahapatra PC, Mallick J, Swain S, Mitra $\mathrm{S}$, Sahoo J. Role of diagnostic hystero-laparoscopy in the evaluation of infertility: A retrospective study of 300 patients. Journal of Human Reproductive Sciences. 2013;6(1):32-4.

4. Tsuji I, Ami K. Miyazaki A. Huzinami N. Benefit of diagnostic laparoscopy for patients with unexplained infertility and normal hystero-salpingography findings. Tohoku J Exp Med. 2009;219.

5. Aleem M, Bashir A. Endometriosis in diagnostic laparoscopy Specialist. 1995;11:103-7.

6. Godinjak Z, Idrizbegovic E. Should diagnostic hysteroscopy be a routine procedure during diagnostic laparoscopy in infertile women? JBMS. 2008;8:44-7.

7. Puri S, Jain D. Laparohysterocopy in female infertility: A diagnostic cum therapeutic tool in Indian setting. Int. J APP Basic Med Res. 2015;5(1):46-8.
8. Wallach EE. The uterine factor in infertility. Fertil Steril. 1972;23:138-58.

9. Brown SE, Coddington CC, Schnorr J, Toner JP, Gibbons W, Oehninger S. Evaluation of outpatient hysteroscopy, saline infusion hysterosonography, and hysterosalpingography in infertile women: A prospective, randomized study. Fertil Steril. 2000;74:1029-34.

10. Romano F, Cicinelli E, Anastasio PS, Epifani S, Fanelli F, Galantino P. Sonohysterography versus hysteroscopy for diagnosing endouterine abnormalities in fertile women. Int $\mathrm{J}$ Gynaecol Obstet. 1994;45:253-60.

11. Mooney SB, Milki AA. Effect of hysteroscopy performed in the cycle preceding controlled ovarian hyperstimulation on the outcome of in vitro fertilisation. Fertil Steril. 2003;79:637-8.

12. Shokeir TA, Shalan HM, EI-Shafei MM. Significance of endometrial polyps detected hysteroscopically in eumenorrheic infertile women. J Obstet Gynaecol Res. 2004;30:84-9.

13. Hinckley MD, Milki AA. 1000 office-based hysteroscopies prior to in vitro fertilization. Feasibility and findings. JSLS. 2004;8:103-7.

Cite this article as: Behuria S, Nayak R. Diagnostic and therapeutic hysterolaparoscopy in evaluation and treatment of female infertility in a tertiary hospital.

Int J Reprod Contracept Obstet Gynecol 2016;5:4189-92. 